\title{
Identifikasi Sebaran Wilayah Kebun Teh Hitam Ortodoks Berbasis Web Sistem Informasi Geografis
}

\author{
Risky Soelaeman ${ }^{1}$, Hermawaty ${ }^{2}$ \\ Program Studi Sistem Informasi STMIK "AMIKBANDUNG"1,2 \\ Jln. Jakarta No. 28 Bandung 40272 INDONESIA \\ Email: riskykenji@gmail.com ${ }^{1}$, emma2003_13@yahoo.co.id ${ }^{2}$
}

\begin{abstract}
ABSTRAK
PT. Perkebunan Nusantara (PTPN) VIII merupakan tempat usaha di bidang agrobisnis teh hitam orthodoks. Permasalahan utama yang dihadapi pada bisnis teh hitam orthodoks adalah dalam pengelolaan informasi. Di kebun teh hitam orthodoks ini, belum adanya informasi tentang kebun dan lokasi kebun. Kepala Afdeling / Kepala Produksi membutuhkan petunjuk letak kebun teh hitam tersebut yang ingin dituju dengan menggunakan Google Maps dan menunjukkan letak koordinatnya. Berdasarkan permasalahan tersebut, penulis memiliki solusi untuk menyelesaikan permasalahannya dengan membuat Sistem Informasi Geografis di PT. Perkebunan Nusantara VIII yang berbasis web. Pada penelitian ini, mengambil lokasi di Kabupaten Subang, yang diharapkan dapat dikembangkan untuk memperoleh informasi lebih lanjut.

Adapun metode yang digunakan dalam mengembangkannya adalah metode prototype untuk membangun sebuah sistem, metode analisa sistemnya menggunakan metode UML (Unified Modelling Language) dan metode analisa masalahnya menggunakan Analisis SWOT (Strength, Weaknesses, Opportunities dan Threat). Metode Prototype dirancang agar dapat menerima perubahan-perubahan dalam rangka menyempurnakan prototype yang sudah ada. Metode UML digunakan untuk memvisualisasi, menspesifikasikan dan pendokumentasian dari sebuah sistem pengembangan perangkat lunak berbasis OO (Object Oriented).

Maka dari itu, hasil akhir dalam terciptanya suatu masalah dan solusi dengan menggunakan metode maupun tools pendukung yang ada, penulis mengimplementasikannya menjadi suatu program, yaitu Sistem Informasi Geografis berbasis web.
\end{abstract}

Kata Kunci : Sistem Informasi Geografis, Agrobisnis, Web.

\section{ABSTRACT}

PT. Perkebunan Nusantara VIII web-based. This Information System is reserved for Head Afdeling / Head of Production who wants to manage information related to orthodox black tea garden. In this study, take location in Subang Regency, which is expected to be developed to obtain more information.

The method used in developing it is prototype method to build a system, system analysis method using UML (Unified Modeling Language) method and problem analysis method using SWOT Analysis (Strength, Weaknesses, Opportunities and Threat). The Prototype method is designed to be able to accept changes in order to perfect the existing prototype. The UML method is used to visualize, specify and document from an OO (Object Oriented) software-based development system. 
Therefore, the end result in the creation of a problem and solution using existing methods and support tools, the authors implement it into a program, called it a webbased Geographic Information System.

Keywords: Geographical Information System, Agribusiness, Web.

\section{PENDAHULUAN}

\subsection{Latar Belakang}

Sistem Informasi memiliki peran yang sangat penting dalam sebuah industri agribisnis. Adapun peran dari Sistem Informasi tersebut yaitu menunjang kegiatan bisnis operasional, menunjang manajemen dalam mengambil keputusan dan menunjang keunggulan strategi kompetitif perusahaan. Berbagai perusahaan sedang mengupayakan dalam menciptakan inovasi baru untuk menjadi unggul dalam mengelola informasi di antara pesaing lainnya yang dapat menimbulkan persaingan yang ketat antara perusahaan-perusahaan yang bergerak di bidang agribisnis.

Saat ini, kebutuhan akan informasi selalu dicari. Informasi mengenai Perkebunan selalu dicari oleh pelaku bisnis. Pelaku bisnis mencari informasi tentang jumlah produksi, luas, pengelola kebun, letak geografis seperti alamat dan lokasinya. Secara geografis wilayah Kabupaten Subang berada pada ketinggian rata-rata 805 mdpl (meter di atas permukaan laut dengan jenis tanah lempung berpasir, topografi berbukit serta memiliki pH sebesar sekitar 5-6 dan tersebar kebun-kebun tani di dalamnya, khususnya terdapat kebun teh hitam ortodoks. Informasi geografis tersebut dilakukan melalui riset di lapangan secara abstrak, hal ini diantaranya adalah disebabkan belum adanya penerapan teknologi sistem informasi geografis di dalamnya, karena belum adanya penerapan teknologi yang mumpuni. Jika salah mengartikan informasi yang didapatkan, pelaku bisnis akan melakukan kesalahan untuk memperoleh informasi maupun akses menuju lokasi perkebunan, akibatnya akan kesulitan dalam mencari lokasi yang tepat.

Pada penelitian penulis memanfaatkan metode sistem informasi geografis berbasis web dimana berperan sebagai pemetaan wilayah kebun tani. Sedangkan web berperan sebagai media dalam sistem yang akan dibangun agar memudahkan dalam mengakses. Pada antar muka (interface) berbasis pemetaan (mapping) diharapkan pengguna dapat mencari informasi-informasi yang berhubungan dengan data-data persebaran wilayah kebun tani di Kabupaten Subang, pengguna dapat 
menggunakan lembaran-lembaran peta yang lebih interaktif dengan fasilitas mengakses objek secara langsung ke suatu titik persebaran kebun tani untuk mendapatkan informasi yang tersedia dapat dengan mudah dipelajari oleh pengguna

\subsection{Teori Pendukung}

Menurut Imat Ruhimat, dalam penelitiannya sistem informasi geogafis berbasis web identifikasi potensi wilyah kabupaten Garut, beliau menyimpulkan bahwa peranan sistem informasi geografis dalam pengembangan potensi dapat digunakan sebagai alat bantu pengambilan tindakan terhadap daerah yang potensial untuk pengembangan lebih lanjut. Sistem informasi geografis berbasis web ini dapat digunakan sebagai alat informasi kepada masyarakat luas.

Menurut M. Mustakin dan Doni Ariyanto, dalam penelitiannya sistem informasi geografis berbasis web untuk pemetaan komoditas pertanian di kabupaten XYZ di Jawa Tengah, mereka menyatakan bahwa Sistem Informasi Geografis (SIG) dibutuhkan untuk dapat mengatasi kesulitan mengidentifikasi potensi komoditas pertanian di setiap kecamatan. Informasi yang dapat diperoleh dari SIG berupa informasi spasial maupun non spasial dan forecasting atau peramalan data pertanian dari tahun-tahun sebelumnya.

\section{Peta}

Peta adalah gambaran permukaan bumi pada bidang datar dengan skala tertentu melalui sistem proyeksi. Peta bisa disajikan dalam berbagai cara yang berbeda, mulai dari peta konvensional yang tercetak hingga peta digital yang tampil di layar komputer. Istilah peta berasal dari bahasa Yunani mappa yang berarti taplak atau kain penutup meja. Namun secara umum pengertian peta adalah lembaran seluruh atau sebagian permukaan bumi pada bidang datar yang diperkecil dengan menggunakan skala tertentu. Sebuah peta adalah representasi dua dimensi dari suatu ruang tiga dimensi.

\section{Sistem Informasi Geografis}

Pengertian Sistem Informasi Geografis (SIG) adalah suatu sistem yang menekankan pada informasi mengenai daerah-daerah beserta keterangan (atribut) yang terdapat 
pada daerah-daerah di permukaan bumi. Sistem Informasi Geografis merupakan bagian dari ilmu Geografi Teknik (Geographical Technique) berbasis komputer yang digunakan untuk menyimpan dan memanipulasi data-data keuangan (spasial) untuk kebutuhan atau kepentingan tertentu. Seiring dengan kemajuan dan perkembangan komputer, SIG telah mengalami kemajuan dan perkembangan yang sangat pesat sehingga merupakan suatu keharusan dalam perencanaan, analisis dan pengambilan keputusan atau kebijakan. Kemajuan dan perkembangan SIG ini didorong oleh kemajuan dan perkembangan komputer, serta teknologi penginderaan jarak jauh melalui pesawat udara dan satelit yang telah dimiliki oleh hampir sebagian besar negara maju di dunia.

SIG memiliki pengertian yang selalu berubah sesuai dengan perkembangannya.

Adapun definisi lain dari SIG adalah sebagai berikut.

1. SIG adalah suatu sistem yang dapat melakukan pengumpulan, penyimpanan, pemanggilan kembali, pengubahan (transformasi) dan penayangan (visualisasi) dari data-data spasial untuk kebutuhan-kebutuhan tertentu,

2. SIG adalah suatu sistem yang berbasis komputer yang digunakan untuk menyimpan dan memanipulasi informasi-informasi geografis,

3. SIG adalah sistem komputer untuk memanipulasi data geografi. Sistem ini diimplementasikan dengan perangkat keras da lunak yang berfungsi untuk akuisisi (Perolehan), verifikasi, kompilasi, perubahan, manajemen, manipulasi, presentasi dan analisis,

4. SIG adalah sistem berbasis komputer yang digunakan untuk menyimpanm, memanipulasi dan menganalisis sistem informasi geografis,

5. SIG adalah sistem teknologi informasi berbasis komputeryang digunakan untuk memproses, menyusun, menyimpan, memanipulasi dan menyajikan data spasial, yaitu data yang memiliki acuan lokasi atau posisi (geo-referensi) dan disimpan dalam basis data serta digunakan untuk berbagai aplikasi.

\section{UML (Unified Modelling Language)}

UML (Unified Modelling Language) adalah sebuah bahasa yang berdasarkan grafik / gambar untuk memvisualisasi, menspesifikasikan dan pendokumentasian dari 
sebuah sistem pengembangan perangkat lunak berbasis OO (Object Oriented). UML sendiri juga memberikan standar penulisan sebuah sistem blueprint, yang meliputi konsep bisnis proses, penulisan kelas-kelas dalam bahasa program yang spesifik, skema database dan komponen-komponen yang diperlukan dalam suatu sistem perangkat lunak. UML adalah salah satu perangkat untuk merancang pengembangan perangkat lunak yang berbasis object-oriented adalah hal yang sangat mendasar dalam model UML, juga merupakan bagian paling Statoil dari sebut model, serta menjelaskan elemen-elemen lainnya dari sebuah konsep atau fisik.

\section{Rumusan Masalah}

1. Bagaimana cara memperoleh informasi dengan menunjukkan letak kebun teh hitam Orthodoks yang ingin dituju menggunakan Sistem Informasi Geografis?

2. Bagaimana implementasi Sistem Informasi Geografis identifikasi sebaran kebun teh hitam orthodoks ke dalam perangkat lunak yang terintegrasi dengan database sehingga menjadi Sistem Informasi yang siap pakai?

\section{Tujuan Penelitian}

Adapun tujuan dari penelitian ini adalah sebagai berikut :

1. Untuk memberikan kemudahan dalam mencari informasi tentang kebun teh yang ada di lingkup PT. Perkebunan Nusantara VIII,

2. Untuk menggambarkan proses pencarian lokasi kebun teh yang berada dalam naungan PT. Perkebunan Nusantara VIII yang sedang berjalan,

3. Untuk mengimplementasikan Sistem Informasi Geografis pemetaan kebun teh di lingkup PT. Perkebunan Nusantara VIII ke dalam bentuk web yang terintegrasi dengan database sehingga menjadi sistem informasi yang siap pakai.

\section{METODE PENELITIAN}

Adapun metode yang digunakan dalam penelitian ini adalah metode prototype untuk membangun sebuah sistem, metode analisa sistemnya menggunakan metode UML (Unified Modelling Language) dan metode analisa masalahnya menggunakan Analisis SWOT (Strength, Weaknesses, Opportunities dan Threat). Metode Prototype dirancang agar dapat menerima perubahan-perubahan dalam rangka 
menyempurnakan prototype yang sudah ada. Metode UML digunakan untuk memvisualisasi, menspesifikasikan dan pendokumentasian dari sebuah sistem pengembangan perangkat lunak berbasis OO (Object Oriented).

\section{A. Proses Pengolahan GIS}

Data spasial yang dibangun akan diterjemahkan ke dalam layer-layer peta digital. Setiap layer memiliki karakteristik spesifik tentang sebuah kelompok suatu obyek. Untuk mengelola web GIS sebaran kebun teh hitam ortodoks khususnya di wilayah Kabupaten Subang terdapat beberapa layer standar yaitu : layer wilayah administrasi, layer blok kebun, layer jalan (arteri dan kolektor), layer sungai dan layer kontur. Proses pengolahannya terbagi menjadi beberapa tahapan, yakni sebagai berikut:

\section{Tahap memasukkan data}

Pada tahap awal pembuatan aplikasi Web GIS ini yaitu tahap memasukkan data. Data merupakan kumpulan dari informasi-informasi yang diperlukan. Data perlu dimasukkan agar terekam dalam sistem sehingga dapat diolah dan menghasilkan suatu output yang dapat digunakan. Data yang dimasukkan dalam tahap awal ini terdiri atas akuisisi data dan proses awal. Data awal yang dibutuhkan disebut dengan database. Sementara bentuk datanya sendiri, yakni data spasial dan data atribut. Dalam tahap memasukkan data ke dalam web GIS terdapat proses yang harus dilakukan antara lain sebagai berikut:

1. Digitasi Peta Dasar

2. Editing

3. Konversi format data

4. Pemberian atribut

\section{Tahap pengelolaan data}

Tahapan yang kedua adalah tahapan pengelolaan data. Tahapan pengelolaan data ini dilakukan ketika data sudah berhasil dimasukkan. Tahapan kedua ini merupakan pengelolaan tahapan dasar. Tahapan ini meliputi proses pengarsipan data menuju database dan proses pemodelan. Pada tahap ini penulis menggunakan perangkat lunak Quantum GIS (QGIS) sebagai pengolahan peta nya, PostgreSQL sebagai 
database nya dan GeoServer untuk menampilkan aplikasinya. Dan tahapnya sebagai berikut:

1. Jalankan QGIS, buat koneksi ke database yang telah dibuat di PostgreSQL dengan menggunakan tool Add PostGIS Layer, kemudian lakukan pengaturan koneksi.

2. Lakukan tes koneksi, jika berhasil maka proses unggah data shapefile format .shp ke database bisa dilakukan.

3. Unggah file .shp ke dalam database yang telah dibuat beserta atribut lainnya agar dapat ditampilkan.

4. Koneksikan seluruh database di dalam PostgreSQL ke perangkat lunak Geoserver.

5. Jalankan program Geoserver, kemudian akses dengan koneksi localhost.

6. Setelah koneksi berhasil, publikasikan seluruh layer yang diperlukan di Geoserver, kemudian pilih publish pada setiap layer.

\section{Tahap pengeluaran data}

Tahapan selanjutnya adalah tahapan pengeluaran data. Tahapan pengeluaran data merupakan tahapan yang masuk ke dalam dua tahapan terakhir dalam tahapan Sistem Informasi Geografis. Tahapan pengeluaran data berarti termasuk ke dalam output proses tersebut. Data yang telah diolah kemudian dikeluarkan, dan disajikan. Dalam tahapan ini, terdapat beberapa proses yang harus dilakukan, antara lain sebagai berikut:

1. Transformasi skala.

2. Generalisasi.

3. Tampilan Perspektif.

Data yang telah melalui proses analisa oleh sistem informasi geografis akan memberikan informasi pada pengguna data sehingga dapat dipakai untuk berbagai kepentingan. Hasil output dari web GIS ini berbentuk display peta yang telah dilengkapi atribut.

\section{B. Perancangan}

Diagram use case keseluruhan dalam sistem informasi geografis yang akan dibangun terdiri dari dua buah aktor, yaitu Kepala Afdeling sebagai admin sistem 
dan Produksi. Untuk lebih jelasnya use case diagram keseluruhan dapat dilihat pada Gambar 1.

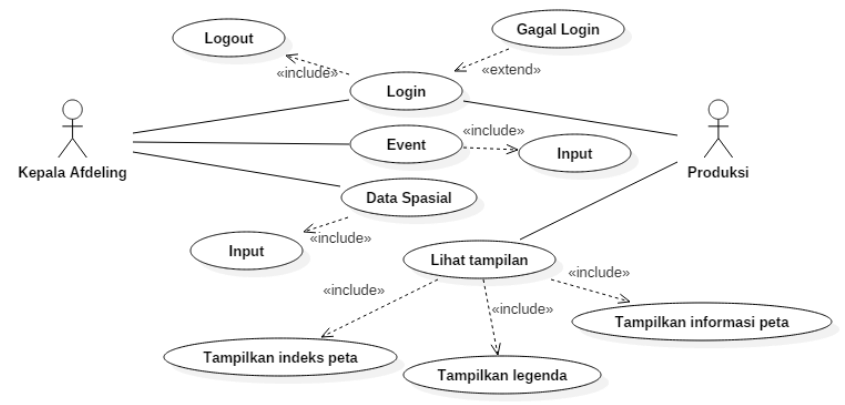

Gambar 1: Diagram Use Case Keseluruhan

\section{HASIL DAN PEMBAHASAN}

\section{Antar Muka Sistem}

Antarmuka aktor sistem merupakan bagian dari sistem komputer yang memungkinkan manusia berinteraksi dengan komputer. Perancangan antarmuka bertujuan untuk memberikan gambaran tentang aplikasi yang akan dibangun, sehingga akan mempermudah dalam mengimplementasikan suatu aplikasi. Rancangan antar muka dalam sistem ini menyajikan menu-menu untuk menampilkan informasi dan peta sebaran teh hitam ortodoks wilayah Jawa Barat dinaungi oleh PT. Perkebunan Nusantara VIII. Perancangan ini terdiri dari 2 menu utama yaitu: Lihat peta dan data spasial. Perancangan menu antarmuka web GIS dideskripsikan pada Gambar 2.

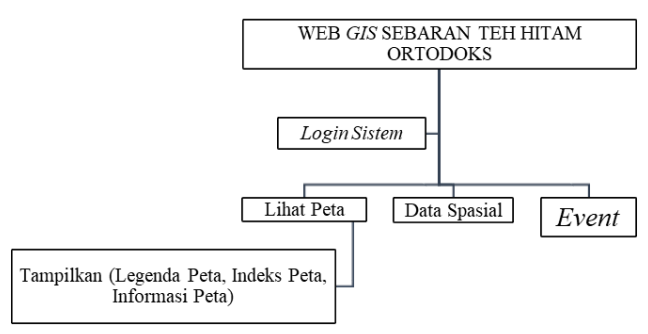

Gambar 2: Diagram Antar Muka Sistem

\section{Implementasi}

Dalam menyusun sebuah program, maka diperlukannya implementasi dalam membuat antar muka sistem, adapun antar muka sistem baik aktor Kepala Afdeling maupun Produksi saat program dibuka pada Gambar 3. 


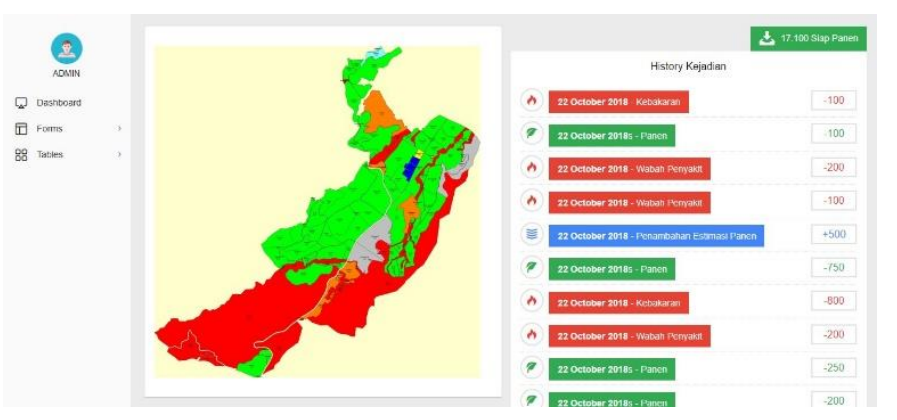

Gambar 3: Implementasi Antar Muka

\section{Pengujian}

Setelah melakukan analisis dan perancangan terhadap sistem, maka dilakukanlah langkah selanjutnya yaitu pengujian sistem dan dilihat kekurangan-kekurangan pada sistem yang dibangun. Pengujian terhadap sistem informasi geografis ini dilakukan dengan menggunakan Pengujian Blackbox, yang merupakan pengujian terhadap sistem dengan cara operasinya apakah berjalan sebagaimana yang diharapkan atau tidak.

\section{Manfaat}

Dengan adanya sistem ini, maka banyak membantu user/pengguna utnuk mencari informasi yang dibutuhkan tentang kebun dan lokasi kebun.

\section{SIMPULAN}

Berdasarkan hasil penelitian yang dilakukan, maka dapat disimpulkan :

1. Dengan adanya sistem informasi geografis ini maka wilayah afdeling menjadi terpola sehingga memberikan kemudahan dalam memperoleh informasi karena adanya proses pengidentifikasi kebun teh hitam Orthodoks.

2. Kepala Afdeling dapat mencari informasi tanpa kesulitan memperolehnya dikarenakan adanya media untuk membantu memvisualisasikan informasi yang dibutuhkan.

3. Sistem informasi geografis bisa membantu kepala produksi yang membutuhkan petunjuk letak kebun teh hitam dengan menggunakan google maps dan langsung ditunjukkan letak koordinatnya. 


\section{DAFTAR PUSTAKA}

SWOT Analysis: Idea Methodology And A Practical Approach, GRIN Verlag, 2009.

W. W. Arrasmuth, Systems Engineering and Analysis of Electro-Optical and Infrared Systems, CRS Press, 2015.

M. N. DeMers, GIS for Dummies, New Mexico State University: John Wiley \& Sons, 2009.

M. L. H. a. R. J. Heiss, The Tea Enthusiast's Handbook: A Guide to the World Best Teas, Ten Speed Press, 2012.

E. Irwansyah, Geographic Information System (GIS) Using IDRISI Software: Application in Coastal Management, Geoinforma, 2012.

K. Jennings, Maps and Geography, New York: Simon and Schuster, 2014.

Munawar, Pemodelan Visual dengan UML, Yogyakarta: Graha Ilmu, 2005.

Sisten informasi Geografis berbasis Web untuk pemetaan komoditas pertanian di Kabupaten XYZ Jawa TengahJISKa, Vol-1 No.1 MEI 2016, Pp.29-40 ISSN $2527-5836$

Sistem Informasi Geografis berbasis web identifikasi potensi wilayah kabupaten Garut, slideshare.net/ruhimatc/jurnal-GIS-dalam bahasa Indonesia 